NASA Technical Memorandum 87048 AIAA-85-1229

\title{
Technology Requirements to be Addressed by the NASA Lewis Research Center Cryogenic Fluid Management Facility Program
}

John C. Aydelott Lewis Research Center Cleveland, Ohio

and

Robert S. Rudland

Martin Marietta

LBRAM" ROPY

SEP 31085

Denver, Colorado

Prepared for the

Twenty-first Joint Propulsion Conference cosponsored by the AIAA, SAE, ASME, and ASEE Monterey, California, July 8-10, 1985 


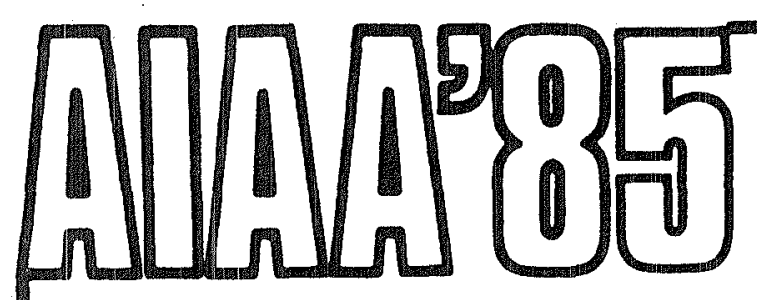

AlAA-85-1229

Technology Requirements to be Addressed by the NASA Lewis Research Center Cryogenic Fluid Management Facility Program John C. Aydelott, NASA Lewis Research Center, Cleveland, $\mathrm{OH}$; Robert S. Rudland, Martin Marietta, Denver, CO

\section{AIAA/SAE/ASME/ASEE 21st Joint Propulsion Conference July 8-10, 1985 / Monterey California}


TECHNOLOGY REQUIREMENTS TO BE ADDRESSED BY THE NASA LEWIS RESEARCH CENTER

CRYOGENIC FLUID MANAGEMENT FACILITY PROGRAM

\author{
John C. Aydelott \\ National Aeronautics and Space Administration \\ Lewis Research Center \\ Cleveland, Ohio 44135
}

and

Robert S. Rudland

Martin Marietta Denver Aerospace

Denver, Colorado 80201

\title{
SUMMARY
}

The NASA Lewis Research Center is responsible for the planning and execution of a scientific program which will provide advanced in-space cryogenic fluid management technology. A number of future space missions have been identified that will require or could benefit from this technology. These fluid management technology needs have been prioritized and a Shuttle attached reusable test bed, the Cryogenic Fluid Management Facility (CFMF), is being designed to provide the experimental data necessary for the technology deve1opment effort.

\section{INTRODUCTION}

Approximately $25 \mathrm{yr}$ ago Lewis initiated a research program intended to provide the technology base for the design and operation of fluid systems in the reduced gravity environment of space. More recently the focus of the program has been on producing the technology which will be required to periodically replenish the cryogenic liquid supply systems on satellites, orbit transfer vehicles (OTV) and manned space platforms that would remain permanently in space.

The "Low-G Fluid Transfer Technology Study," (refs. 1 and 2) completed in 1974, provided conceptual designs of tankers for the on-orbit fueling of an OTV and the resupply of a variety of spacecraft. These potential tanker designs were used to help identify technology gaps and system characteristics critical to on-orbit fluid transfer. The potential problem areas identified included chilldown and subsequent filling of both cryogenic and noncryogenic receiver tanks without excessive liquid loss or pressure rise.

Several subsequent analytical studies have been completed which specifically addressed the problem of reduced-gravity fluid transfer with particular emphasis on systems for managing cryogenic liquids. Reference 3 analyzed a "fluid dynamic" filling technique based on mantaining separation of the liquid and vapor phases within the receiver tank during the entire fill process. For this liquid transfer technique, extremely low liquid transfer flow rates are generaliy required in order that the stability of the liquid-vapor interface is maintained. The low acceleration environment required to provide phase separation could be provided by atmospheric drag, but only at relatively low 
orbital altitudes, or the use of tethers between the Space Station and a Space Vehicle Servicing Facility (ref. 4). In contrast to the "fluid dynamic" technique, references 5 and 6 present the analysis of a "thermodynamic" technique for the on-orbit filling of receiver tanks. This approach is based on the concept of alternately chilling and venting cryogenic tankage until the receiver tank is cold enough that the tank can be filled without venting.

NASA committees, composed of representatives from each field center with an interest in low-gravity fluid management, have periodically reviewed the Lewis program and aided in the formulation of a plan for the acquisition of the required technology. The most recent of these committee activities was the Space Station Technology Steering Committee (ref. 7) commissioned by the office of Aeronautics and Space Technology (OAST). The variety of technology requirements that were identified led to the recommendation that a complete cryogenic liquid transfer system should be employed to provide the experimental data. Because the fluid dynamic and thermodynamic processes associated with the orbital transfer of cryogenic liquids are expected to be highly dependent on the acceleration environment, Shuttle attached experimental transfer systems were conceptually designed (refs. 8 and 9). Based both on anticipated technological return and funding availability, the Cryogenic Fluid Management Facility (CFMF) concept (ref. 10) was selected for subsequent development.

A number of future NASA and DOD missions have been identified that will require or could benefit from advanced in-space cryogenic fluid management technology (refs. 11 and 12). This paper reviews these missions, identifies the corresponding technology needs and discusses the method by which the Lewis fluid management program and CFMF design have evolved to meet these needs. Each of the fluid management technology requirements to be addressed by the CFMF Project has been examined analytically. A computer code, the cryogenic System Analysis Model (CSAM), has been developed to provide predictive capability for the performance of the CFMF as well as for full scale spacecraft employing cryogenic fluid management systems. Preliminary performance predictions for the chilldown and filling of the CFMF receiver tank are contained in this paper.

\section{POTENTIAL APPLICATIONS AND BENEFITS}

Both NASA and DOD mission models include spacecraft which will be boosted to orbit without fluids to minimize weight and optimize thermal performance. The cryogenic fluids will be separately transported to orbit and then must be transferred in the low-gravity environment of space. In other applications cryogenic liquids will be periodically resupplied to extend the useful life of space experiments, satellites and space Station subsystems.

Space Station auxiliary propulsion, electrical energy storage, life support and thermal control subsystems are all potential users of cryogenic liquids. In addition, the Space Station is anticipated to eventually have the capability to service Orbit Maneuvering Vehicles, satellites, and OTVs, providing both cryogenic coolants and propellants. Potential military applications also include cryogenically fueled upper stages as well as space-based weapon systems which may employ cryogenic liquids as reactants, coolants and propellants. 
The OTV payload transportation requirements are anticipated to grow with the evolution of the Space Station. On orbit (Space Station) topping of ground based OTV propellant tanks can be used to increase satellite/payload placement capability. This method can be employed to replace cryogenic propellant boil ... off and/or to overcome Shuttle launch weight restrictions. Eventually, spacebased reusable OTVs having higher energy capability will be required to meet the payload placement capability demands envisioned for the mid-1990s time frame and beyond.

The space-based OTV is an example of a weight critical spacecraft which benefits from relaxed structural requirements. In contrast to ground-based oiv concepts which must be designed to withstand the Shuttle multi-g launch environment fully loaded with propellants, the space-based OTV can be transported to orbit empty and be structurally designed to withstand only the relatively low thrust imposed by its own engine system. A much lighter structural design results for the space-based OTV with a corresponding one to one increase in payload placement capability. The space-based OTV will also have a lighter, more efficient thermal control system due to the fact that fewer tank support struts will be required and the insulation system needs to be designed only for the space environment.

of potentially much greater impact is the projected operational cost savings associated with space-based OTV concepts. A large percentage of the anticipated operating cost for any space-based OTV concept is associated with the expense of transporting propellants to orbit (ref. 13). For ground-based vehicles, which are fully loaded with propellants prior to shuttle ascent, the earth-to-orbit propellant transportation cost is the same as for any dedicated Shuttle payload. However, space-based OTVs are to be fueled at the Space Station from cryogenic storage tanks which can be replenished on an as-available basis. The possibility exists for propellants to be at least partially supplied to the Space Station by scavenging unused propellants from the Shuttle external tank and main propulsion system (refs. 14 and 15). In addition, the transporting of propellants in Shuttle mounted tanks on a space- and weightavailable basis could greatly reduce the cost associated with operating the space-based OTV.

\section{TECHNOLOGY IDENTIFICATION}

Based on the review of future NASA and DOD mission plans, in-space cryogenic fluid management technology requirements were grouped into the three general categories of liquid storage, supply, and transfer. A cryogenic fluid management system which illustrates these three technology categories is shown schematically in figure 1.

\section{Liquid Storage}

Thermal protection. - Heat reaches cryogenic tanks through the tank insulation, the support system, the fluid lines attached to the tank and any other conduction paths such as instrumentation lead wires. Most of the thermal analys is is straightforward and based on adequate experimental data. An exception is heat transfer through thick multilayer insulation systems (MLI). The impact of the Shuttle launch environment on thick MLI blanket performance and the 
degradation of MLI resulting from long-term exposure to the space environment has not been determined.

Pressure control. - Most NASA liquid propellant upper stages control tank pressure by periodic venting. This method of pressure control requires the use of settling rockets to position propellants prior to venting to prevent the loss of liquid. Settling rockets may also be required for propellant acquisition prior to engine start. An approach for management of the effects of heat addition to cryogenic tankage which has potentially much wider application is the use of the thermodynamic vent system (TVS) concept.

In the TVS a small amount of the stored cryogenic liquid is sacrificially evaporated to offset the unavoidable heat addition to the tank. Cryogenic liquid is withdrawn from the tank and passed through a Joule-Thomson valve with a resultant pressure and temperature reduction. This cold two-phase fluid is then introduced into a heat exchanger where evaporation continues and heat absorption takes place before the resulting vapor is vented overboard.

The heat exchanger is typically located either within the tankage insulation (vapor-cooled shield), on the tank wall, or inside the tank. In the first option, most of the incoming heat is intercepted before it reaches the liquid contained in the tank. For the third option, the cryogenic liquid and vapor in the tank are the heat exchanger hot side fluid. This fluid is cooled during operation of the TVS, thus controlling the tank pressure. The on the tank wall heat exchanger TVS concept combines both heat interception and energy removal from the stored cryogen to control tank pressure.

TVS heat exchanger performance, regardless of location, is not expected to be significantly affected by the gravitational environment. However, the in-the-tank heat exchanger option introduces the additional requirement of circulating the fluid in the tank so that effective liquid cooling can take place. Fluid circulation experiments conducted in the Lewis Zero-Gravity Facility have established that the gravitational environment has a significant effect on the liquid motion (ref. 16).

Slosh control. - Future space missions, such as telescope platforms and directed beam weapon systems, will require extremely close control of vehicle attitude. In space very large amplitude liquid motion can result from relatively small disturbances caused by thruster firings for attitude change or orbit correction. It is anticipated that slosh baffles will be required for some spacecraft and that the baffles could significantly impact other fluid management systems.

\section{Liquid Supply}

Direct tank outflow with settling. - During vehicle maneuvers to provide propellant settling, large safety factors are generally applied to the selection of settling rocket thrust level and duration. This operational philosophy yields correspondingly large settling rocket hardware and propellant weight penalties. Utilizing an impirical analysis and data obtained from a Lewis drop-tower program, Sumner (ref. 17) developed estimates of the minimum velocity increment required to achieve liquid settling. The results of this study indicate that the weight penalties associated with propulsive settling could be significantly reduced. However, additional experimental verification of the 
analysis should be undertaken prior to utilizing this technique for vehicle design.

Capillary acquisition devices. - When propellant settling is not practical, other methods must be considered for delivery of single-phase liquid from a tank. The idea of using the liquid retention characteristics of fine mesh screen materials to acquire liquids in a reduced gravity environment was introduced in the early 1960 's. The first use of screen materials for liquid acquisition was to cover the propellant sump at the bottom of propulsive vehicle tanks. The liquid trapped in the sump was used to provide on-orbit engine restart capability regardless of the bulk liquid position in the tank. Once the engine ignited, the resulting thrust settled the propellants refilling the sump and allowing continued engine firing. This general class of liquid positioning device is commonly referred to as a partial acquisition system or start basket.

For applications that require continuous feed of liquids under reduced gravity conditions, it is necessary to design the liquid acquisition device so that it contacts the liquid bulk no matter where the liquid is positioned in the tank. These acquisition devices generally consist of a complete screen liner or multiple channels with screen on one side which are positioned circumferentially inside the tank. This general class of liquid positioning device is commonly referred to as a total communication system.

Fluid dynamic analysis and modeling techniques are well developed for capillary acquisition devices for storable propellants. Systems for cryogenic liquids require the same fluid dynamic analysis; however, concern must also be given to thermal effects since cryogenic liquids will be stored near their boiling point. It may be necessary to avoid heat addition to capillary liquid acquisition devices in order to prevent vapor formation and displacement of 1iquid. The expulsion efficiency (residual determination) and sensitivity to heat addition of fine mesh screen liquid acquisition devices designed for cryogenic applications needs to be established experimentally.

Pressurization. - A pressure differential is required to cause liquid flow between two systems. Common techniques employed involve pressurization of the liquid supply tank or the use of mechanical pumps. For cryogenic systems some pressurization of the supply tank may be required, even if pumps are employed, in order to preclude boiling and subsequent outflow of two-phase fluid.

Inert noncondensible pressurant gases, such as helium, are typically employed for cryogenic systems. However, for space applications involving tanks which will be resupplied prior to being completely drained, a means for removing the noncondensible gas would be required in order to avoid over pressurization of the tank during refill. Autogenous pressurization, using stored liquid which has been vaporized and possibly heated, would eliminate this prob1em. Since the heat and mass transfer phenomena associated with either helium or autogenous pressurization is expected to be highly gravitational dependent, in-space experimentation is required to establish the quantity of pressurant required and the impact of pressurization on the thermodynamic state of the outflowing liquid. 


\section{Liquid Transfer (Thermodynamic technique)}

Transfer line chilldown. - Well established procedures exist for the chilldown of lines for the transfer of cryogenic liquids on earth. However, the effect of a reduced-gravity environment on heat transfer rates and two phase fluid flow phenomena could significantly change the nature of the line chilldown process.

Receiver tank chilldown. - When the tank to which cryogenic liquid is to be transferred is initially empty and warm, the first step in the procedure will be to cool the tank down to an acceptable temperature for the transfer to begin. A small quantity of liquid cryogen is admitted to the previously evacuated tank. This charge is held in the tank allowing transfer of heat from the tank to the cryogenic fluid to take place. All of the cryogenic liquid will be vaporized and the resulting warm vapor is vented to space. This process may be repeated as necessary, depending on the initial temperature and thermal mass of the tank. The temperature to which the tank must be prechilled is determined by the fluid conditions that are desired to exist at the end of the subsequent no-vent fill process. If the transfer is started with the receiver tank at too high a temperature, the final pressure will be excessive or significantly less than a full tank of liquid will result. In addition, a high tank temperature prior to the start of the liquid transfer will yield a higher temperature, lower density liquid in the receiver tank and a reduction in the mass of cryogenic liquid transferred.

During the receiver tank chilldown process heat transfer will occur by three major modes. Initially, the liquid will partially vaporize as it comes into equilibrium with the reduced pressure in the tank. The remaining liquid will tend to break into drops and to spatter against the hot tank wal1, being repelled by the vaporization that occurs during the brief period of contact. The drops of liquid moving through the tank will absorb heat from the vapor and will vaporize as a result. Finally, vapor generated by the initial flashing and by subsequent vaporization will exchange heat with the tank wall by free or forced convection and by conduction. These heat transfer processes are expected to be highly influenced by the gravitationally environment and will also be governed by the fluid properties, liquid injection technique, tank wall temperature and tank size.

Receiver tank no-vent fill. - Examination of the thermodynamics in the receiver tank during a no-vent fill liquid transfer process can be considered in three phases. The first phase, starting at the beginning of transfer, involves vaporization of part of the incoming liquid, or flashing. This occurs because the pressure in the tank is lower than the vapor pressure of the incoming liquid. During this phase, additional vaporization may occur if the walls and internal hardware have not been prechilled to liquid temperature.

Flashing of the liquid continues until the incoming liquid is in equilibrium with the tank pressure. At that point, the second phase begins. Continued inflow of liquid causes compression of the vapor, and the tank pressure will rise above the vapor pressure of the incoming liquid. As the pressure increases, vapor will begin to condense on the tank wall and at the liquid interface, the third phase of the process. When the receiver tank pressure reaches its specified maximum operating limit, further transfer into the tank can occur only as condensation of vapor makes room for more liquid. 
Condensation of vapor is the most important process in the no-vent fill procedure. The tank wall and liquid-vapor interfacial area available for condensation as well as the rate at which condensation occurs will limit the rate at which transfer can proceed. During the highly transient no-vent fill operation, whenever the liquid interface is at a temperature that is below the saturation temperature corresponding to the tank pressure, vapor will condense at the interface. However, this condensation deposits the heat of condensation into the interface layer, and quickly raises its temperature to the saturation point. Further condensation is dependent on transfer of heat from the interface into the bulk of the liquid. Consequently, to enhance this heat transfer, means for promoting mixing should be considered.

Under reduced-gravity conditions the liquid-vapor interface configuration is established primarily by surface tension forces. However, the interface position and area will also be influenced by the flow of liquid into the tank. The interface area is expected to increase due to mixing induced generation of vapor bubbles within the liquid. The bubbles may not completely separate from the liquid or coalesce due to the lack of buoyancy in the reduced-gravity environment. Consequently, determining the effectiveness of mixing methods and the resulting prediction of condensation rates is expected to be more difficult than would be anticipated for earth based experiments.

As the quantity of liquid transferred increases, the volume of the vapor decreases, and as the tank approaches a nearly full condition the total interfacial area, regardless of the mixing mode, decreases. Therefore, it is possible that the rate of liquid transfer will be severely reduced as the tank becomes filled to approximately the 90 percent level.

If on the wall or internal TVS concepts are used for pressure control on the receiver tank they could also be employed to aid in the condensation of vapor during the no-vent fill operation. In addition, TVS designs for the supply tank may include provisions to provide cooling of the liquid as it leaves the supply tank to improve the effectiveness of the receiver tank no-vent fill operation.

Both the fluid dynamic and the thermodynamic processes associated with the transfer of cryogenic liquids are expected to be highly influenced by the gravitational environment. Consequently, development of on-orbit cryogenic fluid transfer capability is dependent on obtaining data on the no-vent filling process in space.

\section{TECHNOLOGY PRIORITIZATION}

The technology requirements identified in the previous section were prioritized on the basis of their impact on future missions and on the necessity to conduct experimentation in the space environment. In general, the highest priority primary technology requirements were considered to be mission enabling and to involve processes which are significantly affected by the gravitational environment. On-orbit cryogenic fluid transfer has been identified as the primary fluid management technology requirement for several future space missions. Consequentiy, the current focus of the Lewis fluid management program is on the development of experimentally verified analytical models which describe the fluid dynamic and thermodynamic processes associated with the on-orbit transfer of cryogenic liquids. 
Inherent in the study of the on-orbit fluid transfer operation is the necessity to provide thermai control, acquisition and expulsion of the cryogenic liquid. These supporting technology requirements were consequently given the next highest priority rating. Technology requirements which were given secondary priority will likely provide in-space fluid management system performance enhancement or reduced operational complexity. Also included in the secondary priority category were technology requirements that are highly mission specific and thus are not strong candidates for inclusion in a general technology development program.

\section{CRYOGENIC FLUID MANAGEMENT FACILITY DESIGN STATUS}

The preliminary design and mission planning for three flights of the CFMF have been completed by Martin Marietta Denver Aerospace under contract to Lewis. The CFMF is a Shuttle attached reusable test bed which consists of four major elements: (1) a cryogenic liquid storage and supply system, (2) the fluid transfer line and receiver tank, (3) a facility control and data acquisition system, and (4) the supporting structure including a subpallet which is attached to a Spacelab pallet for mounting the CFMF in the Shuttle orbiter cargo bay (fig. 2).

Liquid hydrogen has been selected as the CFMF experimental fluid because of its prominent planned use for future NASA and DOD missions. In addition, liquid hydrogen was selected because it presents challenging in-space fluid management requirements due to its low temperature, density and surface tension properties. Obtaining low-g storage and transfer data for hydrogen will, therefore, have general applicability to other cryogenic fluids with the exception of liquid helium.

The CFMF design and mission planning activity has focused on the development of both analytical models and experimental hardware which will provide data for the verification of the analyses. Each flight of the CFMF will employ common hardware with the exception of interchangeable receiver tanks thus allowing parametric investigation of the primary technology requirement, the on-orbit transfer of cryogenic liquids. The NASA Office of Aeronautics and Space Technology has committed funding to support the development of the hardware for the first CFMF mission. Consequently, the detailed design, safety analysis, Shuttle integration planning and analytical modeling for this mission are proceeding. It is anticipated that a new contract to support the hardware fabrication process and CFMF ground test program will be initiated before the end of the 1985 calendar year.

\section{TECHNOLOGY ADDRESSED BY THE CFMF FIRST MISSION}

The currently planned experimental hardware for the initial mission of the CFMF includes a spherical, vacuum jacketed, twenty-two cubic foot liquid hydrogen storage tank and a thirteen cubic foot receiver tank. The cryogenic storage tank assembly, which will provide approximately ninety pounds of liquid hydrogen for the experimentation, incorporates: (1) a vacuum jacket, multilayer insulation and a vapor cooled shield thermodynamic vent system for thermal control, (2) a fine mesh screen total communication device for liquid acquisition and (3) both helium and hydrogen (autogenous) pressurization capability. The receiver tank is a 0.16 scale (based on tank radius) model oTV 
(ref. 18) liquid hydrogen propellant tank which employs two on the wall thermodynamic vent systems for pressure control. Two liquid hydrogen injection or spray systems are contained within the receiver tank (fig. 2) to facilitate the chilldown and filling operation: (1) a set of four tangential spray nozzles mounted on the girth rings which separate the barrel section from the end domes of the tank and (2) a combined ring and central spiral tube which has multiple holes to provide small axial and radial liquid jets.

\section{Primary Technology}

The highest priority technology objectives for the first CFMF mission are: (1) receiver tank chilldown, (2) no-vent fill of an empty receiver tank, (3) refill of a partially full supply tank and (4) refill of a partialiy full receiver tank. Each of these fluid management technology requirements has been examined analytically. A computer code, the Cryogenic System Analysis Code (CSAM) is being developed to provide predictive capability for the performance of the CFMF as well as for full scale spacecraft employing cryogenic liquids.

Numerical modeling. - Analytical models, in theory, can simultaneously solve all the significant equations that describe the behavior of a system. By incorporating the known equations and the best available estimate of the unknown relationships, a model can be developed to predict the results of experimentation. By comparing analytical predictions with experimental results the analytical discrepancies can be identified and the presumed relationships can be modified to improve the analytical model. When a sufficient quantity and variety of test data has been satisfactorily used to develop the analytical mode1, the model can be employed to predict the performance of other similar systems and can be used to aid in the design of full scale prototype spacecraft.

The Martin Marietta developed CSAM computer code is now being used to aid the detailed design of the CFMF. CSAM defines cryogenic liquid storage and transfer systems by a conductor/node network. It includes a transient heat transfer network analysis, internal tank fluid dynamics and a heat exchanger routine which can simulate thermodynamic vent systems. Events and boundary conditions are programmable, permitting simulation of an entire mission. This comprehensive computer code was first used during the detalled design effort for the liquid hydrogen storage and supply system of the CFMF (ref. 19). CSAM is useful in modeling many of the fluid management systems of interest with the current focus on the analysis of receiver tank chilldown and no-vent fill fluid transfer processes.

Receiver tank chilldown. - Two approaches to providing receiver tank chilldown will be experimentally examined during the first CFMF mission. The first chilldown sequence will involve liquid inflow through the tangential nozzles mounted on the receiver tank girth rings. The second chilldown sequence will employ liquid jets emanating from the centrally located axial tubes. Both chilldown sequences will require multiple liquid injection and vent cycles to preclude exceeding allowable receiver tank pressure. Electrical heaters, mounted on the receiver tank wall, will be employed after the first chilldown sequence to heat the receiver tank to the desired starting point temperature for the second chilldown sequence. 
The two liquid injection techniques will provide an experimental determination of the effect of fluid motion on the resulting receiver tank chilldown process. Liquid flow from the tangential nozzles will produce circumferential fluid motion. This fluid motion should persist after the liquid injection is complete thus promoting heat transfer from the tank wall to the hydrogen liquid and vapor. Liquid flow from the axial spray tubes will impinge directly on the tank wall yielding very high wall-to-fluid heat transfer rates initially. However, once the liquid injection is terminated the wall-to-fluid heat transfer rates are expected to decay rapidly. Key instrumentation for this portion of the experimental program include: (1) mass flow metering (both inflow and venting), (2) transfer line pressure and temperature measurements to establish the thermodynamic state of the liquid hydrogen entering the spray system. (3) receiver tank pressure sensors and (4) receiver tank internal and wall temperature measurements.

Figure 3 shows the CSAM predicted fluid and wall average temperatures as a function of time for the first liquid injection cycle. The numerically modeled case presented is for the thirteen cubic foot receiver tank, which weighs $61 \mathrm{lb}$, starting at an initial temperature of $530^{\circ} \mathrm{R}$. The mass of liquid hydrogen injected through the tangential nozzles is limited to a little more than three-tenths of a pound so that the maximum allowable tank pressure of 50 psia is not exceeded.

The CSAM results show that enhanced receiver tank cooling can be achieved by venting the tank several times during each chilldown cycle. By only partially venting the receiver tank the essentially adiabatic depressurization causes cooling of the hydrogen vapor remaining in the tank. If additional time is allowed for tank wall cooling, followed by another adiabatic depressurization, the final tank wall average temperature is reduced for a fixed quantity of injected liquid hydrogen. The timing sequence, quantity of liquid hydrogen required and the resulting tank wall temperature change for each of the eight chilldown cycles for the mission one receiver tank are shown in table I.

No-vent fill of empty tank. - When the receiver tank temperature has been reduced to below $100^{\circ} \mathrm{R}$ nearly all of the tank thermal energy will have been removed. The receiver tank will be vented to near space vacuum, the vent valves will be closed and liquid hydrogen will be introduced into the tank through the tangential nozzles. Key instrumentation for this experimental sequence is identical to that required for the receiver tank chilldown sequence.

The receiver tank filling operation is expected to be highly dependent on the thermodynamic state of the inflowing liquid hydrogen. The test fluid thermodynamic state is primarily controlled by the operating conditions maintained in the storage and supply tank. These operating conditions will be discussed in the following section on supporting technology requirements.

The initial use of the tangential inflow nozzles is intended to promote mixing within the receiver tank, minimizing the rate of pressure rise and thus aiding the pressure driven liquid transfer operation. Inflow through the tangential nozzles is also expected to cause centrifuging of the liquid to the receiver tank walls with the resultant vapor region being centrally located in the tank. Since the liquid-vapor interfacial heat and mass transfer rate will control the resulting changes in tank pressure, it is highly desirable to have a known interface configuration. The liquid centrifuging provides a known 
interface configuration and allows prediction of the surface area available for heat and mass transfer during this portion of the filling operation.

As the receiver tank filling proceeds the tank pressure will rise and it will become necessary to introduce liquid hydrogen through the axial flow system into the vapor region to promote vapor condensation. The optimum point in the fllling sequence will be selected based on numerical results from the CSAM computer code and ground based testing of the CFMF. Figures $4(a)$ and (b) present CSAM results for the filling of the first mission receiver tank. Current CSAM capability allows analysis of individual subsystems only. Consequently, the receiver tank pressure and percent liquid filling are shown as a function of time for a constant supply pressure of 40 psia and a constant liquid hydrogen saturation pressure of 30 psia. The CSAM computer code will eventualiy provide the capability to analyze complete integrated cryogenic liquid transfer systems.

The CSAM simulation presented in figure 4 indicates that the receiver tank can be completely filled because the inflowing liquid is assumed to be maintained at a constant 30 psia saturated condition. In a real cryogenic liquid transfer system, such as the CFMF, the liquid transfer rate will decay as the pressure differential between the two tanks decreases. As the transfer rate decays, the heat addition to the fluid, both in the supply tank and in the transfer line, becomes significant. The liquid saturation temperature will actually rise and complete filling of the receiver tank will not be achieved.

The receiver tank filling operation will terminate when the supply tank and receiver tank pressures are nearly equal. At this time the on the wall thermodynamic vent systems on the receiver tank will be activated to maintain the tank pressure within acceptable limits.

Supply tank refill. - Following the receiver tank filling liquid hydrogen transfer operation, the supply tank will still have an appreciable quantity of liquid remaining in it. Autogenous $\left(\mathrm{GH}_{2}\right)$ pressurization of the supply tank will be used for the receiver tank filling so that no noncondensible gas will have been introduced into the system. The supply tank TVS, which has been designed to have a heat removal capability approximately twice as great as the anticipated heat leak to the suppiy tank, will be commanded to operate at full capacity in order to reduce the supply tank pressure. While the Shuttle reaction control system (RCS) rockets are fired to provide liquid settling, the CFMF receiver tank will be pressurized with gaseous helium and some of the liquid hydrogen test fluid will be transferred back into the supply tank. Key instrumentation for this portion of the experimental program include: (1) mass flow metering, (2) transfer line pressure and temperature measurements to establish the thermodynamic state of the liquid hydrogen entering the supply tank acquisition device, (3) supply tank pressure sensors and (4) supply tank internal temperature measurements.

A primary concern associated with the supply tank refilling operation will be to ensure that no vapor bubbles have been trapped within the liquid acquisition device since subsequent outflow from the supply tank would yield twophase fluid. Following this second liquid transfer operation, the supply tank will be pressurized with gaseous hydrogen which will thus subcool the liquid and hopefully condense any vapor bubbles in the acquisition device. A short outflow sequence from the supply tank will follow to ensure that only liquid is flowing from the acquisition device. If two-phase fluid is detected in the 
transfer line (to be discussed in the following "Supporting Technology" section) the flow will be terminated and the supply tank pressure will be further increased by using helium pressurant. The helium pressurization should provide additional subcooling of the liquid hydrogen and condensation of any hydrogen vapor contained in the total communication liquid acquisition device. Once again a short outflow sequence will be required to determine the quality of the fluid being supplied from the acquisition device.

Receiver tank refill. - The supply tank refill operation discussed above will be terminated when approximately one-half of the liquid hydrogen contained in the receiver tank has been transferred. Continuous operation of the receiver tank TVS will reduce the tank pressure while keeping the tank at a uniform temperature.

Following a period of time allocated to the evaluation of the liquid hydrogen storage capability of both tanks, the Shuttle RCS rockets will once again be fired to provide liquid settling in the receiver tank. While periodic RCS firing is provided, the receiver tank will be slowly vented overboard to reduce the tank pressure and greatly reduce the concentration of noncondensible helium gas in the tank.

The second filling (refilling) of the receiver tank will be characterized by the use of an operating scenario that should result in the tank being nearly filled. In contrast to the more readily analyzable approach used during the initial receiver tank filling, the refilling operation will employ: (1) continuous operation of the supply tank TVS to provide maximum cooling of the liquid hydrogen, (2) helium pressurization to the supply tank maximum operating pressure to provide maximum liquid subcooling and the highest possible liquid transfer rates, (3) continuous operation of the receiver tank TVS to both eliminate any heat addition to the tank through the insulation system and to provide some condensation of vapor within the tank and (4) use of both the tangential and axial liquid spray systems to maximize the fluid mixing and vapor condensation within the receiver tank. Key instrumentation for this experimental sequence is identical to that required for the earlier discussed receiver tank chilldown and no-vent fill operations.

\section{Supporting Technology}

Low-gravity fluid management technology that is required to support the primary cryogenic liquid transfer objectives of the first CFMF mission consists of: (1) tank pressurization, (2) thermal conditioning of the liquid cryogen, (3) total communication liquid acquisition device performance, (4) transfer line chilldown, (5) receiver tank settling and outflow, (6) venting of noncondensible gas and (7) mass flow metering instrumentation performance. Although it is necessary to include these technology areas in order to meet the primary CFMF fluid management experimental objectives, these supporting technology requirements were given a lower priority rating. This lower priority rating is reflected in a minimum amount of dedicated instrumentation and limited variation of the experimental parameters for each technology.

Tank pressurization. - Both hydrogen and helium gas will be employed to provide pressurization of the liquid hydrogen storage and supply tank. The gas will be provided from high pressure storage bottles. The rate of gas consumption will be determined by thermodynamic analysis based on the pressure and 
temperature of the gas remaining in the bottles. Hydrogen pressurant will be used for the first liquid transfer operation so that no noncondensible gas will be introduced into the supply tank prior to the planned supply tank refill operation. Helium pressurant will be provided to the receiver tank for the supply tank refilling operation and to the supply tank for the subsequent receiver tank refilling operation.

Because of the difference in the thermodynamic properties of hydrogen and helium gas, less hydrogen pressurant is predicted to be required for a given liquid expulsion requirement even though some of the hydrogen pressurant will condense. Interfacial heat and mass transfer will cause energy to be absorbed from either pressurant by the stored liquid. However, the liquid heating is expected to be greater if hydrogen pressurant is employed because the tank pressure and the partial pressure of the hydrogen gas are the same and the liquid interfacial temperature will be equal to the saturation pressure at tank conditions. If helium pressurant is employed the tank pressure is equal to the sum of the hydrogen and helium partial pressures and the interfacial temperature will be lower, corresponding to the hydrogen partial pressure.

The quantity of hydrogen or helium pressurant gas required and the subsequent amount of liquid heating is expected to be highly dependent on the gravitational environment. The liquid-vapor interface configuration, and thus the surface area available for heat and mass transfer, is also highly dependent on the acceleration environment. In addition, under low-gravity conditions the pressurant gas, which is injected at the "top" of each tank, may be bubbled directly into the liquid cryogen thus promoting energy exchange. Pressure and temperature sensors internal to both CFMF tanks will be used to determine the heat and mass transfer rates of interest.

Liquid thermal conditioning. - The filling or refilling of a cryogenic tank is expected to be highly influenced by the temperature of the liquid entering the tank. The temperature of the inflowing liquid will be primarily determined by the storage conditions at the liquid source. However, the liquid temperature will also be influenced by the just discussed pressurization technique employed, the heat absorbed in the transfer line between the two tanks and any liquid cooling that may be provided. Pressure and internal temperature sensors throughout the CFMF transfer system will be employed to determine the effect of the above on liquid thermal conditioning.

Both CFMF mission one tanks will have thermodynamic vent systems intended to maintain the liquid hydrogen experimental fluid saturated at 30 psia prior to any transfer operation. Pressurization of the liquid source tank to 40 or 50 psia will be accomplished prior to the initiation of all chilldown, filling and refilling operations. The transfer line will be well insulated so that heat addition to the flowing cryogenic liquid will be negligible.

The CFMF supply tank TVS, although previousiy described as a vapor-cooled shield, is actually a unique design. The TVS consists of two flow legs and multiple heat exchangers; one leg is designed to operate continuously and absorb the majority of the projected system heat flux while the second has approximately twice the cooling capacity of the first and is designed to operate on demand based on tank pressure. The cold fluid for both TVS legs is first used to cool the outlet region of the supply tank to ensure that no heat reaches the liquid acquisition device where it could cause vapor formation. The number one TVS flow is routed from an outlet cooling manifold to the vapor- 
cooled shield. The number two TVS flow is routed through a heat exchanger mounted directly on the outside of the supply tank wall and then to the vaporcooled shield. During the receiver tank refilling operation both supply tank heat exchangers will be activated to experimentally evaluate their effect on the temperature of the liquid leaving the supply tank.

Acquisition device performance. - It is essential that single phase liquid hydrogen be provided by the fine mesh screen total communication liquid acquisition device in the supply tank during the receiver tank filling and refilling operations. Two mass flow metering instruments will be included in the liquid hydrogen transfer line to measure the flow rates and provide control of valves in the line which will interrupt the flow if two-phase fluid is detected.

Fluid dynamic analysis of the supply tank acquisition device has indicated that vapor should not be ingested through the screens until the remaining liquid occupies less than one-half percent of the tank volume. Following the receiver tank refill operation, supply tank liquid will be flowed overboard until two-phase fluid flow is detected in the transfer line. The supply tank outflow valve will be closed and the number two supply tank TVS will be activated. By continuing to monitor the rate of gaseous hydrogen flow through the supply tank TVS until the tank is depleted, the quantity of liquid which remained in the tank when acquisition device breakdown occurred can be determined.

Transfer line chilldown. - Prior to each liquid transfer operation it will be necessary to cool down the lines, valves and instrumentation between the two tanks. Although two-phase heat transfer is known to be highly influenced by the gravitational environment (ref. 20), it is not reasonable to include the observational port in the CFMF transfer line that would be required to study this phenomena. Temperature instrumentation will provide engineering data on heat transfer rates during the chilldown process, but little scientific understanding of the two-phase flow phenomena will be provided.

Liquid settling and outflow. - The supply tank refill operation requires that single phase liquid be provided from the receiver tank. This experimental sequence will be performed while the Shuttle RCS rockets are periodically fired, thus providing both liquid settling (reorientation) and acquisition (positioning) so that the receiver tank outflow sequence can be successfully accomplished. The low-gravity fluid dynamic phenomena associated with both the settling and outflow operations will be numerically modeled using the NASA SOLA-VOF computer code (ref. 21). Experimental data obtained from the CFMF will be compared with the numerical predictions and hopefully provide increased confidence in the use of numerical modeling techniques. Liquid level sensors in the receiver tank and the mass flow metering instrumentation in the transfer line will be the primary source of data for this experimental investigation.

Helium venting. - Helium pressurant is currently planned to be used to expel the liquid hydrogen from the receiver tank during the supply tank refilling operation. The noncondensible helium gas will have to be vented from the receiver tank before refill of this tank can be effectively accomplished. The Shuttle RCS rockets will once again be fired to provide liquid settling in the receiver tank and then venting will be initiated. The instrumentation required to control the venting process and determine how effectively the helium has been removed from the receiver tank has not yet been selected. It may be necessary to provide timing of the venting process based solely on ground test 
data and then infer the effectiveness of the on-orbit venting operation from the results of the subsequent refilling operation.

Liquid flow measurement. - Successful achievement of all of the CFMF primary technology development goals hinges on the availability of suitable liquid flow measurement instrumentation. A survey of sources for cryogenic liquid mass flow meters quickly establishes that devices qualified for flight on the Shuttle do not exist. The current CFMF design includes the use of two different flow meter concepts mounted in the transfer line. One instrument, which uses the drag body approach to measure volumetric flow rates, has acceptable accuracy for use with liquid hydrogen and should be readily qualifiable for space flight. The second candidate flow meter employs an approach based on measurement of flow tube motion caused by coriolis forces. This instrument has potentially superior accuracy while actually measuring mass flow rates including the ability to meter two-phase flow, but has not yet been tested with liquid hydrogen or been qualified for use on the shuttle.

\section{Secondary Technology}

The CFMF is a complete liquid hydrogen storage and transfer system designed to operate in the space environment. As such it offers the opportunity for the evaluation of some advanced fluid management technology that of itself would not be of high enough priority to justify in-space testing. Included in this secondary technology category are: (1) tank insulation, (2) storage tank temperature and pressure control and (3) liquid hydrogen quantity gaging instrumentation.

Multi-layer insulation (MLI). - Cryogenic storage systems employing MLI have been used for a variety of in-space applications. In general, these systems have also incorporated vacuum jackets so that the very low pressure that is required within the insulation system is established before launch. One exception is the Centaur vehicle that was orbited by the Titan rocket. This Centaur vehicle configuration used an insulation system on the liquid hydrogen tank composed of three layers of MLI. The CFMF receiver tank will have a sixty layer MLI blanket. Measurement of the in-space venting rate from the receiver tank, together with limited temperature instrumentation, will provide an indication of how thick MLI blankets react both to the launch environment and exposure to the hard vacuum of space.

Thermodynamic vent systems (TVS). - Once again, cryogenic storage systems employing TVS have been used for a variety of in-space applications. The majority of these TVS have been of the vapor-cooled shield variety. The TVS on both CFMF tanks will provide performance data for temperature and pressure control concepts which include on the tank wall heat exchangers. Key instrumentation for this investigation includes: (1) gas flow metering in the TVS lines, (2) pressure and temperature measurements within the TVS heat exchangers and (3) both supply and receiver tank pressure and temperature sensors.

Quantity gaging. - The current low-gravity approach for maintaining an inventory of the fluid contained in tanks is to continuously integrate the mass flow leaving the system and subtract the total from the known initial fill level. For systems like an OTV servicing facility, which will be periodically partially drained and refilled, this approach is probably not feasible because of accumulating errors in flow measurement. Also, the integrating technique 
cannot account for any leakage from the system. Consequently a true liquid quantity gaging device is expected to be highly desirable for some future space missions. The Johnson Space Center is currentiy responsible for a program intended to develop liquid gaging instrumentation for both cryogenic and noncryogenic applications. Assuming this instrument development activity is successful, the CFMF will provide an ideal test bed for the in-space evaluation of the most promising concepts.

\section{SUBSEQUENT CFMF MISSIONS}

The planning and preliminary hardware design for two additional CFMF missions has been completed. The primary technology requirements addressed by these missions parallel the first mission with the emphasis on providing additional parametric data on the in-space transfer of cryogenic liquids. This objective will be achieved by replacing the mission one receiver tank with: (1) a larger tank and (2) a tank which contains a partial acquisition device. This approach provides parametric variation of both receiver tank size and mass, the two key variables identified by the analytical modeling effort. Experimental data will also be obtained which will help establish the impact of parametric variations on all of the mission one supporting and secondary technology areas.

The subsequent CFMF missions will provide the opportunity to experimentally investigate the refill of an empty supply tank. A key element of this portion of the program will be the filling of the total communication liquid acquisition device and the elimination of any trapped vapor. In addition, during one of the follow-on missions the heat flux to the supply tank will be increased as tank depletion is approached. This would be accomplished through the use of electrical heaters mounted on the tank or by helium injection into the multilayer insulation system. The effect of heat addition on the expulsion efficiency of the liquid acquisition device can then be determined.

The mission which incorporates a partial liquid acquisition device into the receiver tank is intended to provide advanced fluid management technology for space-based orbit transfer vehicles. The acquisition device must be capable of being filled in-space along with the rest of the tank. In addition, the performance of the partial acquisition device will be evaluated to determine its: (1) ability to contain liquid under adverse accelerations and heat addition, (2) refilling characteristics during a settling maneuver, and (3) expulsion efficiency.

\section{TECHNOLOGY REQUIREMENTS NOT ADDRESSED BY CFMF}

Most of the identified low-gravity fluid management technology requirements that will not be addressed by the CFMF project fall into two general categories: (1) those technologies that are associated with the long term storage of cryogenic liquids in-space and thus require testing time that exceeds that available with shuttle attached payloads and (2) technology intended specifically for the in-space management of liquid helium. The NASA Lewis and Marshall field Centers are currently sponsoring complimentary contracted studies intended to provide conceptual hardware designs and the planning for long term cryogenic liquid storage technology development missions. The technology development mission hardware would be transported to orbit by 
the Shuttle and attached to the initial space Station. This experimental program would provide a long term cryogenic storage technology demonstration prior to the completion of the final design of the growth space Station orbit transfer vehicle servicing facility. The Ames Research Center is sponsoring an in-space liquid helium transfer technology development program which, because of the unique properties of helium, parallels the CFMF project effort.

Shuttle mid-deck experiments are likely candidates for the investigation of methods for controlling liquid motion which results from the application of low level accelerations. Transparent tanks, containing slosh control baffles, could be photographically examined to provide insight into the motion of fluids in response to Shuttle maneuvers.

\section{CONCLUDING REMARKS}

The need for on-orbit cryogenic liquid transfer technology to support future NASA and DOD missions has been established. The fluid dynamic and thermodynamic processes associated with this technology are expected to be complex and highly gravitationally dependent. Consequently, it is essential that experimentally verified analytical tools and design criteria be made available before initiating development of advanced space systems requiring resupply of cryogenic liquids in space. This goal is being pursued, as part of the NASA Lewis's low-gravity fluid management technology program, through the development of both analytical models, which will describe fluid transfer system performance, and the CFMF experimental hardware which will be used to obtain the data necessary to verify or modify, as required, the analytical models. The mission planning and preliminary hardware design for three CFMF missions has been completed. The detailed hardware design, safety analysis and Shuttle integration activities for the first CFMF mission are nearing completion. A new contract between Lewis and Martin Marietta Denver Aerospace, to cover the CFMF first mission hardware fabrication and ground test program, is expected to be signed before the end of calendar year 1985.

Thus far the analytical models have proven to be valuable tools, aiding the design of the CFMF. Analytical projections of CFMF and OTV liquid transfer operations are being employed to aid in the selection of experimental hardware and operating parameters. The CFMF hardware will be approximately full-scale for many of the identified applications, with the obvious exception of the space-based OTV and its servicing facility. Because of the prominence of the space-based OTV within NASA's future program plans, the selection of a suitable size for subscale experimental apparatus is often a point of controversy. From an operational point of view, the quantity of cryogenic liquid required to accomplish receiver tank chilldown will be only a few percent of the total receiver tank capacity. This fact suggests that during the early operating phases of full-scale orbital cryogenic systems requiring resupply, a conservative approach can be employed to overcome any uncertainty that might still exist in the analytical models employed during the system design. Very little cryogenic liquid loss penalty will accrue from prechilling the receiver tank to near the liquid temperature, prior to initiating the liquid transfer operation, with a corresponding significant increase in confidence in successfully completing the tank filling. Once some experience has been gained with the ful1scale systems, the amount of conservatism employed can be relaxed. 


\section{REFERENCES}

1. Stark, J.A., "Low-G Fluid Transfer Technology Study," General Dynamics/Convair, San Diego, CA, CASD-NAS-76-014, May 1976. (NASA CR-134911)

2. Stark, J.A., "Low-G Fluid Transfer Technology Study," Summary. General Dynamics/Convair, San Diego, CA, CASD-NAS-76-017, May 1976. (NASA (R-135020)

3. Cady, E.C. and Miyashiro, H.H., "Filling of Orbital Fluid Management Systems," McDonne1-Douglas Astronautics Co., Huntington Beach, CA, MDC-67374, Aug. 1978. (NASA CR-159405)

4. Fester, D.A., Rudolph, L.K., Tegart, J.R., and Abbott, P.W., "Tethered Orbital Refueling Study," Martin Marietta Aerospace, Denver, CO, MCR-85-512, Jan. 1985 .

5. Merino, F., Blatt, M.H. and Thies, N.C., "Filling of Orbital Fluid Management Systems," General Dynamics/Convair, San Diego, CA, CASD-NAS-78-010, July 1978. (NASA CR-159404)

6. Merino, F., Riesberg, J. and Hill, M., "Orbital Refill of Propulsion Vehicle Tankage," General Dynamics/Convair, San Diego, CA, GDC-CRAD-80-001, Feb. 1980. (NASA CR-159722)

7. Wright, R.L. and Mays, C.R., eds., "Space Station Technology 1983," NASA CP-2293, 1984 .

8. Drake, G.L., Bassett, C.E., Merino, F., Siden, L.E., Bradley, R.E., Carr, E.J. and Parker, R.E., "Conceptual Design of an Orbital Propellant Transfer Experiment," Vol. 2, General Dynamics/Convair, San Diego, CA, GDC-ASP-80-013, Aug. 1980 (NASA CR-165150)

9. Willen, G.S., Riemer, D.H. and Hustvedt, D.C., "Conceptual Design of an In-Space Cryogenic Fluid Management Facility, "Beech Aircraft Corp., Boulder, CO, BAC-ER-14967, Apr. 1981. (NASA CR-165279)

10. Eberhardt, R.N., Gille, J.P., Bailey, W.J. And Berry, R.L., "Cryogenic Fluid Management Facility Concept Definition Study (CFMF), Mart in Marietta Denver Aerospace, Denver, C0; MCR-83-536, Dec. 1983. (NASA (R-174630)

11. Steinbronn, 0., Hujsak, E. and Maloney, J.: "Operations/Servicing of a Space-Based OTV on a Space Station." General Dynamics Convair, 34th Congress of the International Astronautic Federation, IAF Paper 83-39, Oct. 1983.

12. Sponable, J.M. and DeWispelare, A.R., "Optimizing the Space Transportation System with a Space Fueling Station and Tug," AIAA Paper 84-1324, June 1984.

13. "Definition of Technology Development Missions for Early Space Station; Orbit Transfer Vehicle Servicing," Vol. 2, General Dynamics/Convair, San Diego, CA, GDC-SP-83-052-VOL-2, June 1983. (NASA CR-170863) 
14. "STS Propellant Scavenging Systems Study," Vo1. 2, Martin Marietta Denver Aerospace, Michoud Division, New Orleans, LA, Feb. 1985.

15. "Space Transportation System (STS) Propellant Scavenging System Study." Vo1. 1, Rockwe11 International/Space Transportation Systems Division, Downey, CA, STS 84-0570-VOL-1, Jan. 1985. (NASA CR-171848-VOL-1)

16. Aydelott, J.C., "Modeling of Space Vehicle Propellant Mixing," NASA TP-2107, 1983.

17. Sumner, I.E., "Liquid Propellant Reorientation in a Low-Gravity Environment," NASA TM-78969, 1978.

18. Davis, E.E., "Future Orbital Transfer Vehicle Technology Study," Vol. 2, NASA CR-3536, 1982.

19. Eberhardt, R.N., Bailey, W.J., and Fester, D.A., "Cryogenic Fluid Management Experiment," Martin Marietta Denver Aerospace, Denver, CO, MCR-81-597, oct. 1981. (NASA CR-165495)

20. Bradshaw, R.D. and King, C.D., "Conceptual Design for Spacelab Two-Phase Flow Experiments," General Dynamics/Convair, San Diego, CA, CASD-NAS-77-025, DeC. 1977. (NASA CR-135327)

21. Hotchkiss, R.S., "Simulation of Tank Draining Phenomena with the NASA SOLA-VOF Code," LOS Alamos Scientific Laboratory, Los Alamos, NM, LA-8163-MS, DeC. 1979. 
TABLE 1. - PREDICTEDa CFMF MISSION ONE RECEIVER TANK CHILLDOWN CHARACTERISTICS

\begin{tabular}{|c|c|c|c|c|c|c|c|c|c|}
\hline Chilldown cycle & 1 & 2 & 3 & 4 & 5 & 6 & 7 & 8 & 1 to 8 \\
\hline $\begin{array}{l}\text { Initial wall temperature }\left({ }^{\circ} \mathrm{R}\right) \\
\text { LH2 mass injected (16) } \\
\text { Time to inject (min) } \\
\text { Time to hold (min) } \\
\text { Time to vent (min) } \\
\text { Final wall temperature }\left({ }^{\circ} \mathrm{R}\right)\end{array}$ & $\begin{array}{c}530 \\
0.31 \\
0.56 \\
2.67 \\
3.52 \\
490\end{array}$ & $\begin{array}{c}490 \\
0.36 \\
0.58 \\
2.50 \\
3.52 \\
430\end{array}$ & $\begin{array}{c}430 \\
0.42 \\
0.67 \\
2.52 \\
3.56 \\
371\end{array}$ & $\begin{array}{r}371 \\
0.48 \\
0.75 \\
2.58 \\
3.60 \\
317\end{array}$ & $\begin{array}{c}317 \\
0.54 \\
0.83 \\
2.75 \\
3.63 \\
268\end{array}$ & $\begin{array}{c}268 \\
0.62 \\
1.00 \\
2.96 \\
3.67 \\
220\end{array}$ & $\begin{array}{r}220 \\
0.96 \\
1.24 \\
3.05 \\
3.78 \\
167\end{array}$ & $\begin{array}{c}167 \\
1.09 \\
1.76 \\
2.54 \\
3.84 \\
91\end{array}$ & $\begin{array}{r}530 \\
4.78 \\
7.39 \\
21.57 \\
29.12 \\
91\end{array}$ \\
\hline
\end{tabular}

$a_{L}$ iquid supply pressure equals 40 psia; Liquid saturation pressure equals 30 psia; Maximum reçeiver tank pressure equals 50 psia; Receiver tank mass equals $61 \mathrm{lb}$; Receiver tank volume equals $13 \mathrm{ft}^{3}$. 


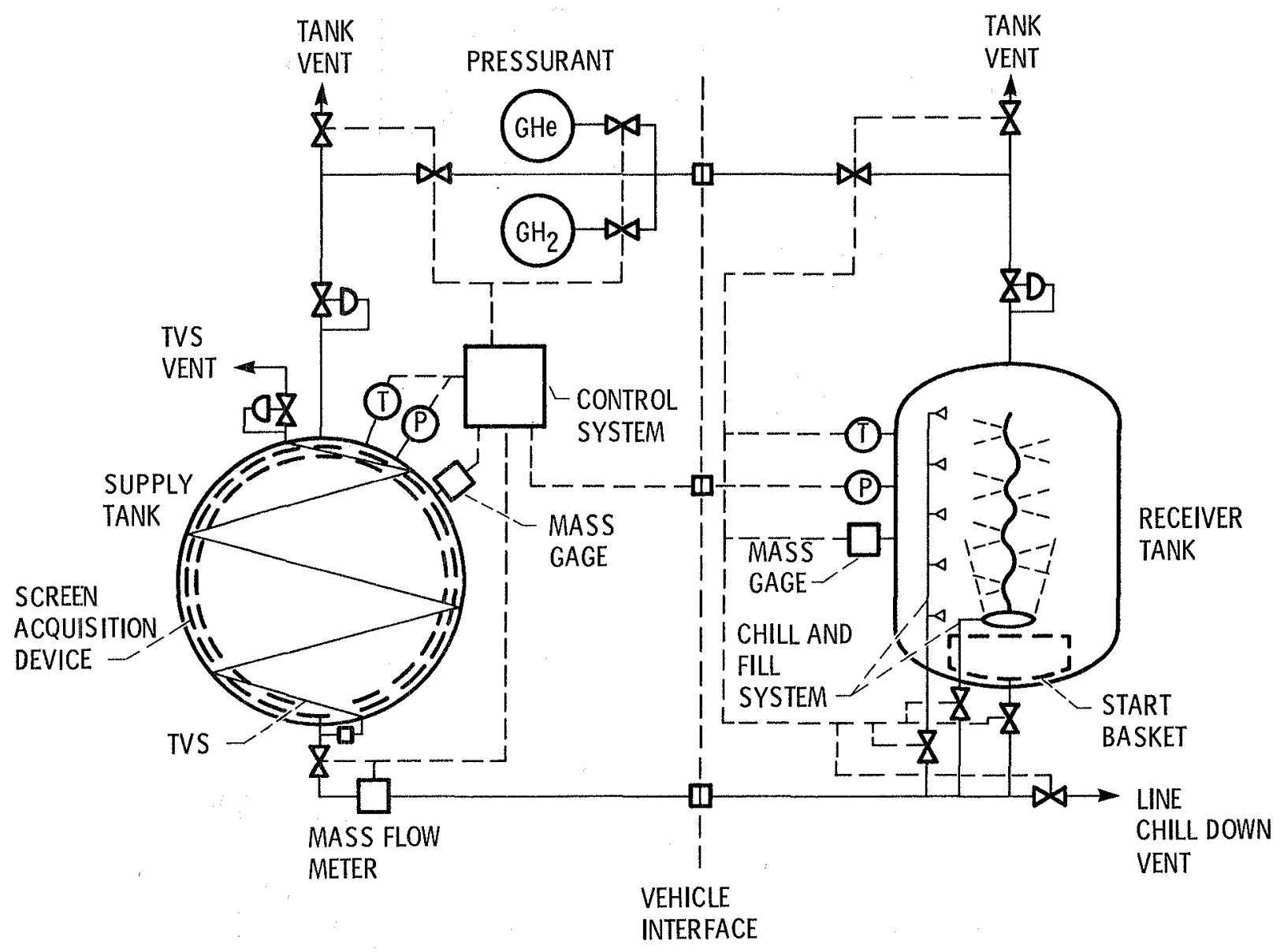

Figure 1. - Cryogenic fluid management systemis concept schematic. 


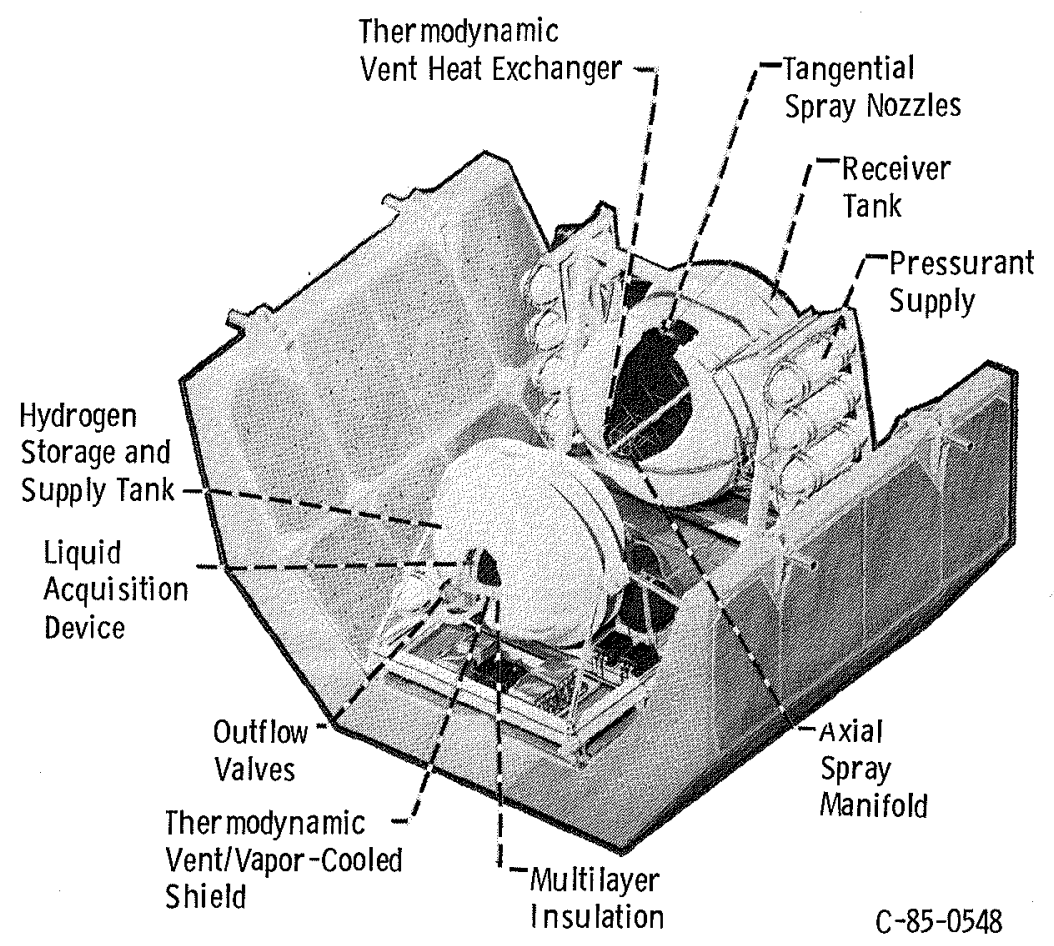

Figure 2. - Cryogenic fluid management facility.

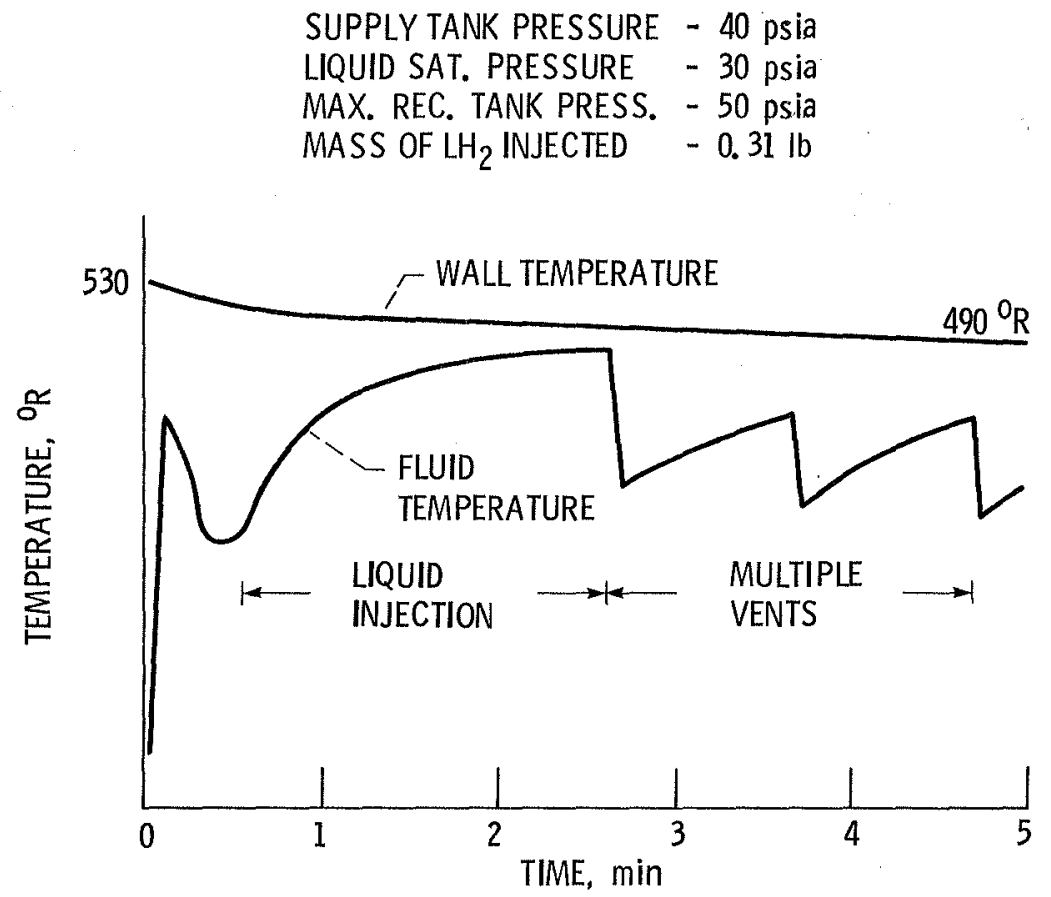

Figure 3. - First chilldown cycle for mission one receives tank (CSAM prediction). 
SUPPLY TANK PRESSURE - 40 psia

LIQUID SAT. PRESSURE - 30 psia

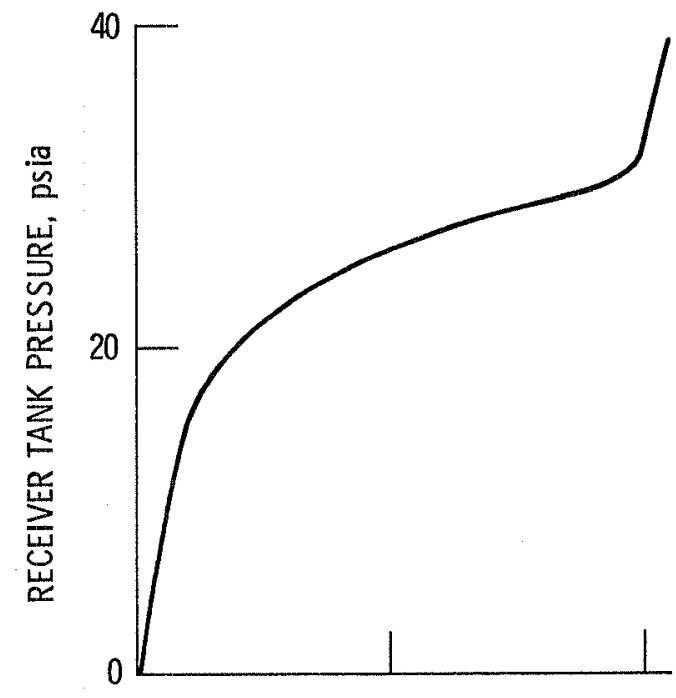

(a) Tank pressure vs time.

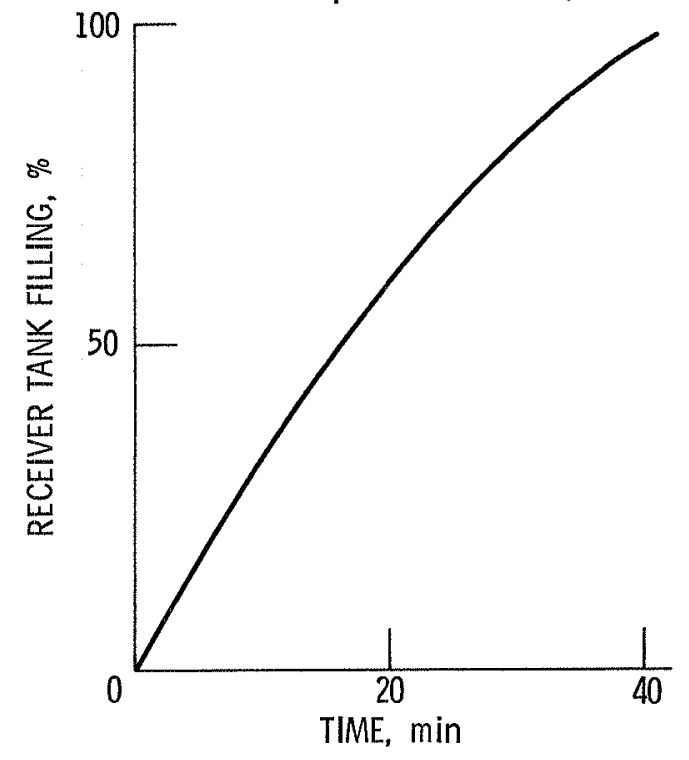

(b) Tank filling vs time.

Figure 4. - Mission one receiver tank filling (CSAM prediction). 


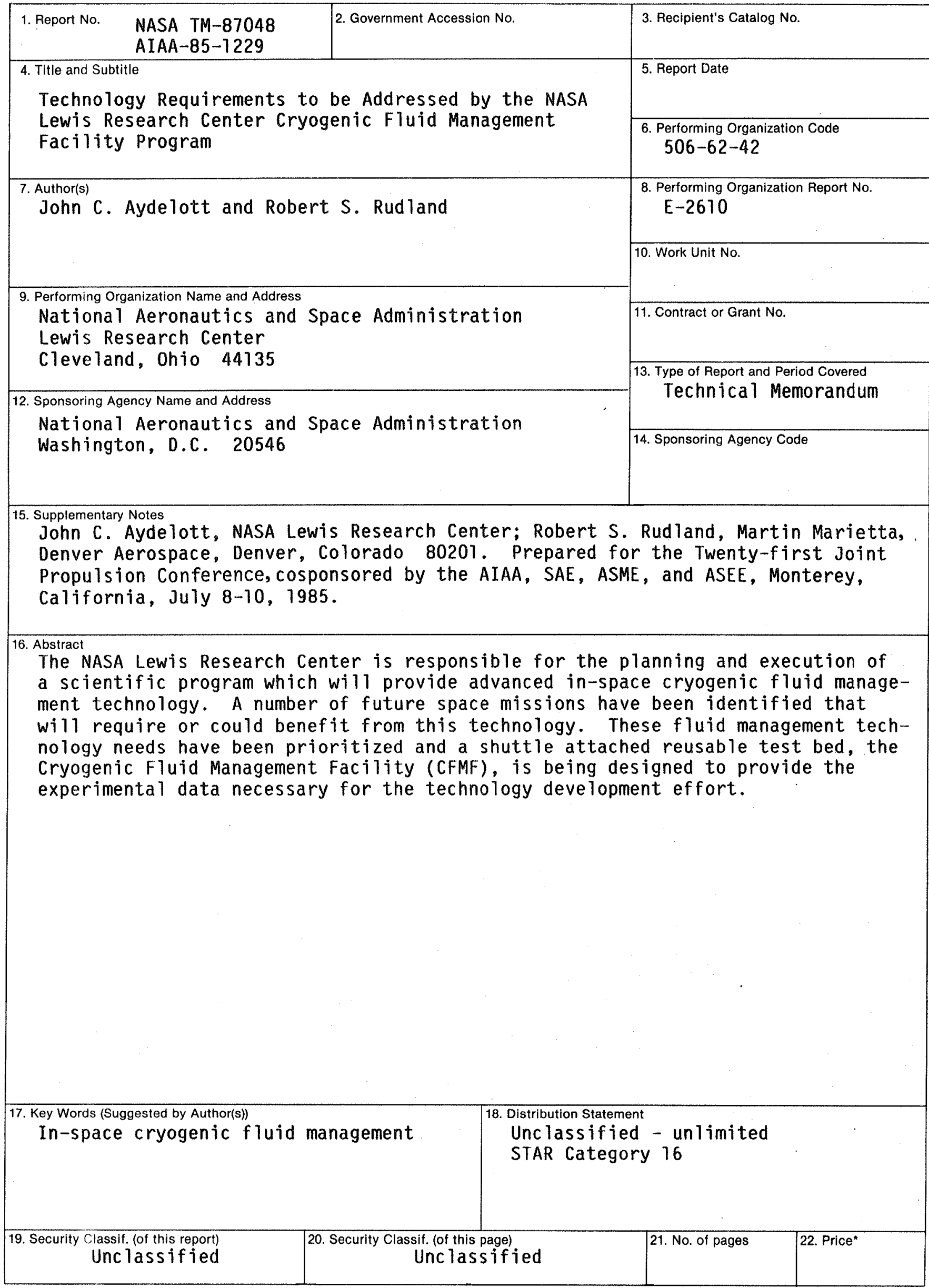

${ }^{\star}$ For sale by the National Technical Information Service, Springfield, Virginia 22161 
End of Document 